\title{
Spatial Variability Study of Duty Cycle in GSM 900 and 1800 MHz Bands in Rural and Urban Environments
}

\author{
N. Faruk', Y. Imam-Fulani' ${ }^{2}$ I. A. Sikiru³, A.A. Oloyede ${ }^{4}$, Q.R. Adebowale ${ }^{5}$, L. A. Olawoyin ${ }^{6}$, A. \\ Abdulkarim $^{7}$ and Y. A. Adediran 8 \\ 1,2,4,5,6 Department of Telecommunication Science, University of Ilorin, Ilorin, Nigeria \\ ${ }^{3}$ Department of Information and Communication Science, University of Ilorin, Ilorin, Nigeria \\ ${ }^{7}$ Department of Electrical Engineering, Ahmadu Bello University, Zaria Nigeria \\ ${ }^{8}$ Department of Electrical and Electronics Engineering, University of Ilorin, Nigeria
}

\begin{tabular}{l} 
Article Info \\
\hline Article history \\
Received M \\
Revised Ap \\
Accepted A \\
\hline Keyword: \\
Duty Cycle \\
GSM band \\
Rural \\
Urban \\
Spatial
\end{tabular}

Corresponding Author:

N. Faruk,

Department of Department of Telecommunication Science,

University of Ilorin, Ilorin, Nigeria

Email: faruk.n@unilorin.edu.ng

\begin{abstract}
This paper examines the spatial variability of duty cycle in the GSM 900 and $1800 \mathrm{MHz}$ bands within Kwara State, Nigeria. The results show spatial variance in the duty cycle with average occupancies of $1.67 \%, 17.76 \%$, $10.55 \%$ and $0.39 \%, 11.00 \%$ and 5.11 in the rural, urban and all locations for 900 and $1800 \mathrm{MHz}$ bands. Findings also show that there is very high positive correlation between rural 900/1800 MHz and urban 900/1800 MHz. But very high negative correlations exits between urban 900 and rural 1800, and urban 1800 and rural 1800 . There is a weak and negative correlation between rural and urban $900 \mathrm{MHz}$, rural-urban 1800. These results clearly show the abundance of unutilised spectrum within the GSM bands. Therefore, regulatory commissions should adopt flexible spectrum reuse strategy to relax the regulatory bottlenecks to maximize the scarce radio resources in the licensed bands, especially for rural network deployments
\end{abstract}

Copyright (c) 2018 Institute of Advanced Engineering and Science. All rights reserved.

\section{INTRODUCTION}

Globally, there is unprecedented growth in mobile data traffic, mostly driven by increase of dataintensive devices, such as tablets and smartphones. Efficient usage of the scarce electromagnetic spectrum is necessary for sustenance of more advanced services such as the Internet of Things (IoT), Internet of Vehicle (IoV), remote sensing and many others. However, despite the notion of the scarcity of the radio spectrum, considerable portion of the spectrum set available for wireless communications have been largely underutilized. This underutilization arises due to the current command and control model that largely protects the licensed spectrum owners who may not use the spectrum at all times in all places [1]. This model fails to address the secondary spectrum market opportunities that could not only provide more spectral spaces for the aforementioned services but could also bridge digital divide in most developing economies. The gap is widening as the majority of the unconnected are in the rural areas with communities characterised by extreme poverty, lack of, or limited, social services and infrastructure [2].Thus, it becomes highly necessary to develop techniques that will enhance efficient spectrum utilization, free more spectral spaces that could meet the need for the exponential growth in global mobile data traffic and be used as a tool for meeting up the Sustainable Development Goals (SDGs).Such flexible spectrum regime has been identified as the driver for solving these issues [3]. 
In an effort to tackle the foregoing issues, Cognitive Radio (CR) approach was introduced [4]. The basic underlying idea of $\mathrm{CR}$ is to give room for unlicensed access to some unoccupied licensed bands temporarily or spatially in a favorable, non-interfering and symbiotic manner [5]. In recent time, spectrum occupancy measurement and survey has experienced a rapid growth in Africa, Asia and Europe [4-9]. However most of the researches have not significantly explored spectrum opportunities on the GSM bands. More so, considering the economic viability of the sub $3 \mathrm{GHz}$ spectrum $(1.5 \mathrm{GHz}$ to $3 \mathrm{GHz}$ ), it would be uneconomical to deploy these bands in the rural environments as it leads to high deployment and operating costs [10]. Fortunately, spectrum refarming in the GSM band is still possible as in contrast to the global view to explore only Television White Spaces (TVWs). This has been introduced and demonstrated in [11-12]. It is worthy acknowledging the efforts of Martin in [13] that examined how the spatio-temporal properties of spectrum holes affects the basic communication needs of a secondary spectrum user. Also, Babalola et al. [14-15] studied the temporal variation of duty cycle in the TV band and Faruk et al. [16] conducted a large scale spectrum survey in the rural and urban locations spanning $50 \mathrm{MHz}-6 \mathrm{GHz}$. In [17], a 15-day measurement was conducted outdoors at Selcuk University, Faculty of Engineering building, Konya. The measurements were conducted in both urban and suburban areas covering VHF and UHF bands. After the analysis of the measurement data, it was observed that the part of spectrum lower than $1 \mathrm{GHz}$ is used massively. However, spectrum part above $1 \mathrm{GHz}$ is almost idle. Measurements conducted in the urban area in context of spectrum occupancy resulted in $18.07 \%$ and $11.17 \%$ for both VHF and UHF respectively. For the suburban area, the spectrum occupancy results area $9.80 \%$ and $10.84 \%$ for both VHF and UHF respectively. Attiah et al [18] investigated the implementation of a flexible hybrid mmWave spectrum sharing access (HMSSA) strategy for 5G networks. In [19], spectrum occupancy measurements were conducted in different classes of urban environments in Melbourne, Australia. The uniqueness of this investigation is that the measurement was conducted on a mobile vehicle for assessment on spatial perspective considering a wide frequency band which ranges from $400 \mathrm{MHz}$ to $6000 \mathrm{MHz}$.

In this paper, we examinedthe spatial variability of spectrum occupancies (duty cycle)in the GSM $900 \mathrm{MHz}$ and $1800 \mathrm{MHz}$ bands in some selected rural and urban areas in Kwara State, Nigeria. The objective of the paper is to explore spectral opportunities in the GSM band for refarming or secondary reuse and to study if there is correlation between the variability indices across the bands in different locations. These would guide policy makers to make more informed decisions on the spectrum opportunities that may arise in the GSM bands.

\section{METHODOLOGY}

\subsection{Measurement Setup}

Agilent N9342C Handheld Spectrum Analyzer (HSA) was used as the receiver. The analyser has a frequency span of $100 \mathrm{kHz}$ to $7 \mathrm{GHz}$ and with a display average noise level of $-164 \mathrm{dBm} / \mathrm{Hz}$. The measurement setup and settings used are identical in both rural and urban locations. The analyzer uses energy detection to directly sense the received signal level in $\mathrm{dBm}$. It is capable of displaying the spectrograph of signals. It also has both in-built GPS (global positioning system) for location features.

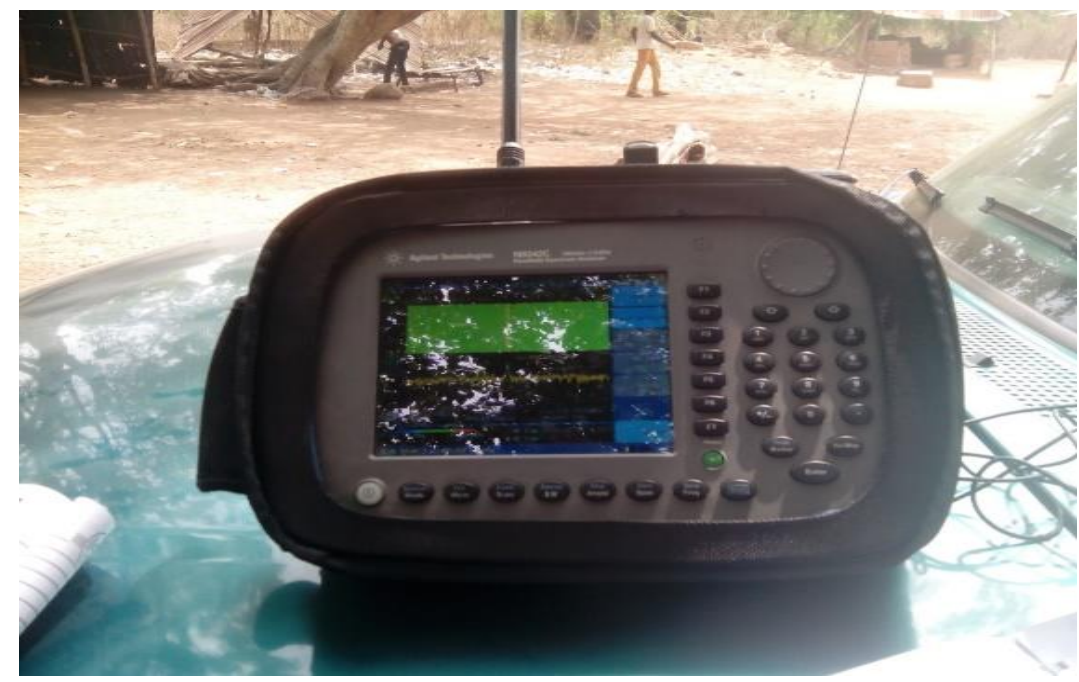

Figure 1. Agilent N9342C Spectrum analyzer

However, for improved location accuracy, an external GPS was connected to it. An external storage device was used to save the log files generated by spectrum analyser as shown in Figure 1. 


\subsection{Measurement Locations}

The measurements were all conducted outdoors at strategic rural and urban locations in Kwara state, Nigeria. Table 1 shows the measurement sites and type of environment considered, with their respective coordinates. Table 2 shows the frequency bands considered. Five rural locations visited are within 30 miles (about $50 \mathrm{~km}$ ) radius from the metropolis.

Table 1. Location Visited

\begin{tabular}{|c|c|c|c|}
\hline Location & Type & Coordinate & Identifier \\
\hline Adio village & Rural & $4^{\circ} 29^{\prime} 42^{\prime \prime} \mathrm{E} 8^{\circ} 46^{\prime} 40^{\prime \prime} \mathrm{N}$ & LOC 1 \\
\hline Malete Village & Rural & $4^{\circ} 31^{\prime} 16^{\prime \prime} \mathrm{E} ; 8^{\circ} 38^{\prime} 49^{\prime \prime} \mathrm{N}$ & LOC 2 \\
\hline Alamote Village & Rural & $4^{\circ} 29^{\prime} 42^{\prime \prime} \mathrm{E} 8^{\circ} 22^{\prime} 34^{\prime \prime} \mathrm{N}$ & LOC 3 \\
\hline OdoOke Village & Rural & $4^{\circ} 31^{\prime} 55^{\prime \prime} \mathrm{E} 8^{\circ} 17^{\prime} 09^{\prime \prime} \mathrm{N}$ & LOC 4 \\
\hline Lagiki, Village & Rural & $4^{\circ} 33^{\prime} 02^{\prime \prime} \mathrm{E} 8^{\circ} 16^{\prime} 46^{\prime \prime} \mathrm{N}$ & LOC 5 \\
\hline University Quarters & Urban & $4^{\circ} 38^{\prime} 47^{\prime \prime} \mathrm{E} 8^{\circ} 27^{\prime} 49^{\prime \prime} \mathrm{N}$ & LOC 6 \\
\hline University of Ilorin & Urban & $4^{\circ} 67^{\prime} 60^{\prime \prime} \mathrm{E} 8.48^{\prime} 74^{\prime \prime} \mathrm{N}$ & LOC 7 \\
\hline Pipeline & Urban & $4^{\circ} 35^{\prime} 07^{\prime \prime} \mathrm{E} 8^{\circ} 27^{\prime} 57^{\prime \prime} \mathrm{N}$ & LOC 8 \\
\hline Kwara Stadium & Urban & $4^{\circ} 32^{\prime} 29^{\prime \prime} \mathrm{E} 8^{\circ} 28^{\prime} 36^{\prime \prime} \mathrm{N}$ & LOC 9 \\
\hline
\end{tabular}

The urban locations were specifically chosen due to high activity of mobile users. This is to reflect the reality of the spectrum usage.

Table 2. Service Bands Considered

\begin{tabular}{lll}
\hline Service Bands & $\begin{array}{l}\text { Frequency } \\
\text { range }(\mathrm{MHz})\end{array}$ & $\begin{array}{l}\text { Bandwidth } \\
(\mathrm{MHz})\end{array}$ \\
\hline GSM 900 UL & $835-915$ & 80 \\
GSM 900 DL & $925-960$ & 35 \\
GSM 1800UL & $1710-1785$ & 75 \\
GSM 1800DL & $1805-1880$ & 75 \\
\hline
\end{tabular}

\subsection{Data Collection and Processing}

During data collection, the sensed signals are collected and stored in external drive for processing. The unprocessed data are presented in a $2 \mathrm{X} 2$ matrix form with element of the received signal power for each frequency and at specific time slot, $\left(f_{\mathrm{i}}, t_{\mathrm{j}}\right)$. During data pre-processing stage, the received data was mined to filter noisy data entries, transposed and sorted. The preamplifier was set and appropriate resolution bandwidth chosen. For each sweep, 1500 frames were collected. Each frame has 114 time slots as represented by the received signal power matrix given by Equation (1).

$$
P=\left(\begin{array}{ccccc}
P\left(f_{1}, t_{1}\right) & . & . & . & P\left(f_{1}, t_{j}\right) \\
\cdot & . & \cdot & \cdot & \cdot \\
\cdot & \cdot & \cdot & \cdot & \cdot \\
\cdot & . & . . & \cdot & \cdot \\
P\left(f_{i}, t_{1}\right) & . & . & . & P\left(f_{i}, t_{j}\right)
\end{array}\right)
$$

The energy detection technique was used as the sensing approach due to its simplicity and ease of computation. Moreover, it has been the most widely used by many researchers. Among the 1500 frames collected for each location per band, 50 frames were selected at random within the sample space. This is because the frame size above 50 was found to have insignificant impacts on the average duty cycle since 10 frames can still provide satisfactory results [20].

Equation (2) was used to obtain the decision ' $\Omega$ ' of the output of the energy detector. This is achieved by satisfying the hypothesis $\left(\mathrm{H}_{1}\right.$, signal is present or $\mathrm{H}_{0}$, signal is absent). For the detection threshold, we used $5 \mathrm{~dB}$ above the mean measured noise level. This threshold was found to provide optimum duty cycle prediction [20] as its prediction was on the borderline, not under estimation as obtained with $3 \mathrm{~dB}$ or overestimation when $10 \mathrm{~dB}$ was used [20].

$$
\Omega_{D}= \begin{cases}\mathrm{H}_{1}, & \text { if } P>\lambda_{j} \\ \mathrm{H}_{o}, & \text { if } P<\lambda_{j}\end{cases}
$$

Then, the duty cycle was obtained as: 
$\Psi(x, f, t)=\frac{1}{M} \sum_{\mathrm{N}} \sum_{i=1}^{\tau} \Omega_{D}\left(f_{i}, t_{j}\right)$

Where $\Psi(x, f, t)$ represent the duty cycle for specific frequency of a given location at specific time. $\Omega_{D}\left(f_{i}, t_{j}\right)$ is the sample of power of a given frame, when $P\left(f_{i}, t_{j}\right)>\lambda_{j} . M$ is the total observation period. $\tau$ is the signal duration and $N$ is the frame number.

\section{RESULTS AND DISCUSSION}

The results of the various occupancy measurements in the GSM $900 \mathrm{MHz}$ and $1800 \mathrm{MHz} \mathrm{DL}$ for both the rural and urban locations in Ilorin Kwara State are shown in Tables 3 and 4. In Table 3, a duty cycle of $0.07 \%$ was obtained for LOC1 (rural), a significant increase (6.9\%) was observed in LOC 2. LOCs 4 to 5 were completely unoccupied with duty cycle of $0 \%$. The reason for this spatial variation is that LOC 2 , being a rural area, has experienced technological developments including being the host to a state university in Kwara state, Nigeria.

Table 3. Duty Cycle Results for GSM $900 \mathrm{MHz}$

\begin{tabular}{|c|c|c|c|c|}
\hline LOCATION & $\begin{array}{l}\text { LOCATION } \\
\text { TYPE }\end{array}$ & $\begin{array}{l}\text { DUTY } \\
\text { CYCLE } \\
(\%)\end{array}$ & $\begin{array}{lr}\text { AVERAGE } & \text { DUTY } \\
\text { CYCLE } & \text { PER } \\
\text { LOCATION TYPE }\end{array}$ & $\begin{array}{l}\text { AVERAGE } \\
\text { DUTY } \\
\text { CYCLE }\end{array}$ \\
\hline LOC 1 & RURAL & 0.07 & \multirow{5}{*}{$1.67 \%$} & \multirow{9}{*}{$10.55 \%$} \\
\hline LOC 2 & RURAL & 6.91 & & \\
\hline LOC 3 & RURAL & 1.39 & & \\
\hline LOC 4 & RURAL & 0 & & \\
\hline LOC 5 & RURAL & 0 & & \\
\hline LOC 6 & URBAN & 9.04 & \multirow{4}{*}{$17.76 \%$} & \\
\hline LOC 7 & URBAN & 8.04 & & \\
\hline LOC 8 & URBAN & 19.28 & & \\
\hline LOC 9 & URBAN & 34.69 & & \\
\hline
\end{tabular}

Table 4. Duty Cycle Results for GSM $1800 \mathrm{MHz}$

\begin{tabular}{llllrl}
\hline LOCATION & LOCATION & Duty & AVERAGe & Duty & Average \\
& TyPe & CyCle & CyCle & Per & Duty \\
& & $(\%)$ & Location TyPe & CyCle
\end{tabular}

\begin{tabular}{llll|l}
\hline LOC 1 & RURAL & 0.69 & & \\
LOC 2 & RURAL & 1.24 & & \\
LOC 3 & RURAL & 0 & $0.39 \%$ & \multirow{2}{*}{$5.11 \%$} \\
LOC 4 & RURAL & 0 & & \\
LOC 5 & RURAL & 0.02 & & \\
\hline LOC 6 & URBAN & 0.12 & $11.00 \%$ & \\
LOC 7 & URBAN & 0.1 & & \\
LOC 8 & URBAN & 11.89 & & \\
LOC 9 & URBAN & 31.9 & & \\
\hline
\end{tabular}

The results show that the GSM 900MHz band is slightly occupied in LOC1 and most occupied in the LOC 2, while all other rural locations were completely unoccupied. For urban locations, LOCs 6 and 7 exhibit high occupancy level. But a quite higher occupancy rateof $19.28 \%$ and $34.69 \%$ were observed in LOCs 8 and 9 respectively. This is because the locations considered (i.e. 8 and 9) are residential and commercial areas respectively within the metropolis, as such high activities are expected. Average occupancies of $1.67 \%$ and $17.76 \%$ were recorded in the rural and urban locations respectively with an overall of $10.55 \%$ in all locations. 
Table 4 provides duty cycle for GSM $1800 \mathrm{MHz}$ DL across the rural and urban locations. Similar findings were obtained for rural and urban locations. As expected, the spectrum is occupied in the urban areas and highly underutilised in the rural locations. The occupancies obtained in the case of GSM $900 \mathrm{MHz}$ are quite high than $1800 \mathrm{MHz}$ across all locations. This is an indication that the $900 \mathrm{MHz}$ band is more utilised. The average occupancies of $0.39 \%, 11.00 \%$ and $5.11 \%$ were measured respectively for the rural, urban and across the nine locations.

Table 5. Pearson's Correlation Matrix

\begin{tabular}{lrrrrr}
\hline & \multicolumn{2}{c}{ Rural } & Rural & \multicolumn{1}{c}{ Urban } & \multicolumn{1}{c}{ Urban } \\
& $900 \mathrm{MHz}$ & $1800 \mathrm{MHz}$ & $900 \mathrm{MHz}$ & $1800 \mathrm{MHz}$ \\
\hline Rural & $900 \mathrm{MHz}$ & 1.0000 & 0.8003 & -0.54026 & -0.5081 \\
Rural & $1800 \mathrm{MHz}$ & 0.8003 & 1.000 & -0.81047 & -0.7780 \\
Urban $900 \mathrm{MHz}$ & -0.54026 & -0.8104 & 1.0000 & 0.9986 \\
Urban $1800 \mathrm{MHz}$ & -0.50811 & -0.7780 & 0.998574 & 1.0000 \\
\hline & $* *$ Correlation is significant at the 0.01 level (2-tailed).
\end{tabular}

**. Correlation is significant at the 0.01 level (2-tailed).

In Table 5, we provide the Pearson's correlation coefficient matrix of the duty cycle across the bands and locations. From the table, we could see that there is very high positive correlation between rural $900 \mathrm{MHz}$ and rural $1800 \mathrm{MHz}$ bands, urban $900 \mathrm{MHz}$ and urban $1800 \mathrm{MHz}$ with correlation coefficients of 0.8 and 0.9 respectively. However, very high but negative correlations were obtained for urban $900 \mathrm{MHz}$ and rural 1800 $\mathrm{MHz}$, and then urban $1800 \mathrm{MHz}$ and rural $1800 \mathrm{MHz}$. A weak and negative correlation was obtained for rural and urban $900 \mathrm{MHz}$. The correlation for rural-urban $1800 \mathrm{MHz}$ was also negative but higher than for 900 $\mathrm{MHz}$ band.

Figures 2 and 3 show the cumulative distribution function of the received signal strength for six locations, three rural and three urban, for GSM $900 \mathrm{MHz}$ and $1800 \mathrm{MHz}$ bands respectively. From both figures, LOC 6 recorded the best signal quality based on this metric. These results indicate that higher duty cycle does not directly mean better signal quality, as the duty cycle is a measure of occupancy (i.e. when the received signal exceeds the threshold value defined). Therefore, values of $-60 \mathrm{dBm}$ and $-90 \mathrm{dBm}$ could mean the same occupancy. In other words, methodology in computing the duty cycle metric did not cater for temporal variation of the received Signal Level (RSS).

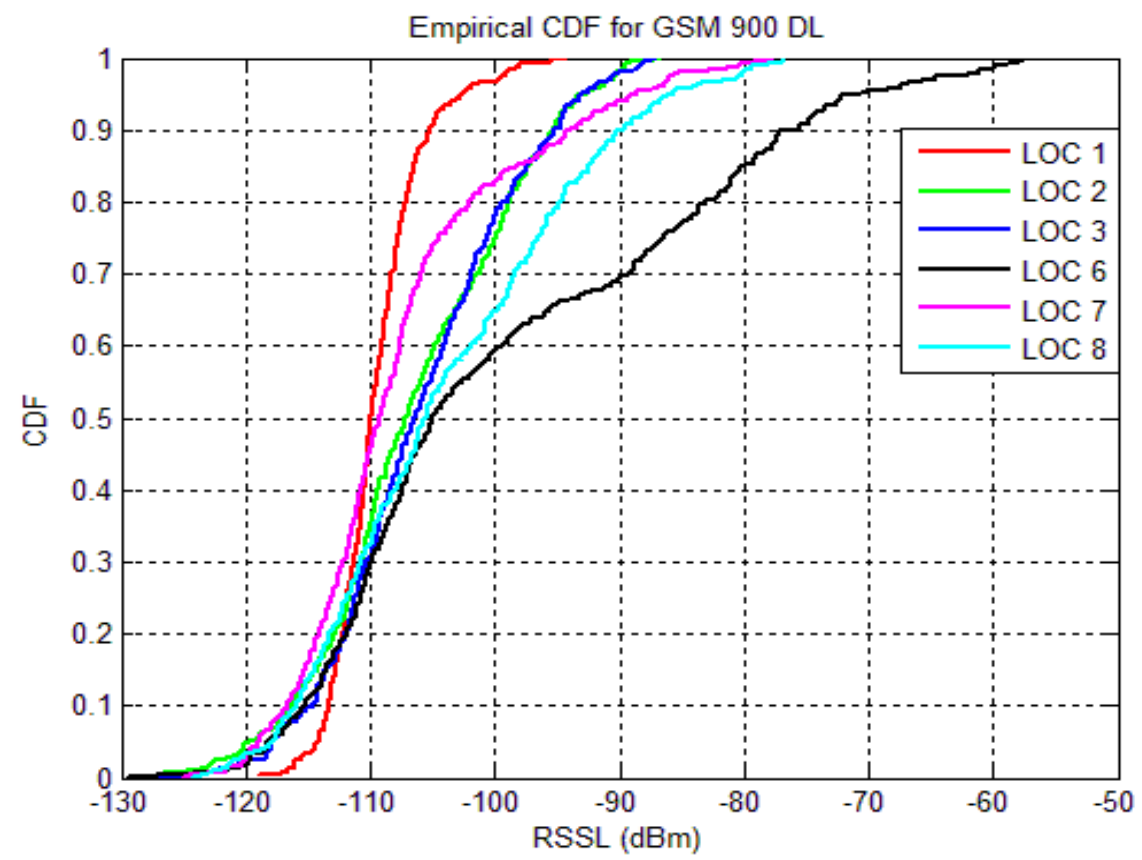

Figure 2. Cumulative Distribution for Received Signal Strength in the GSM $900 \mathrm{MHz}$ Band for selected Locations 


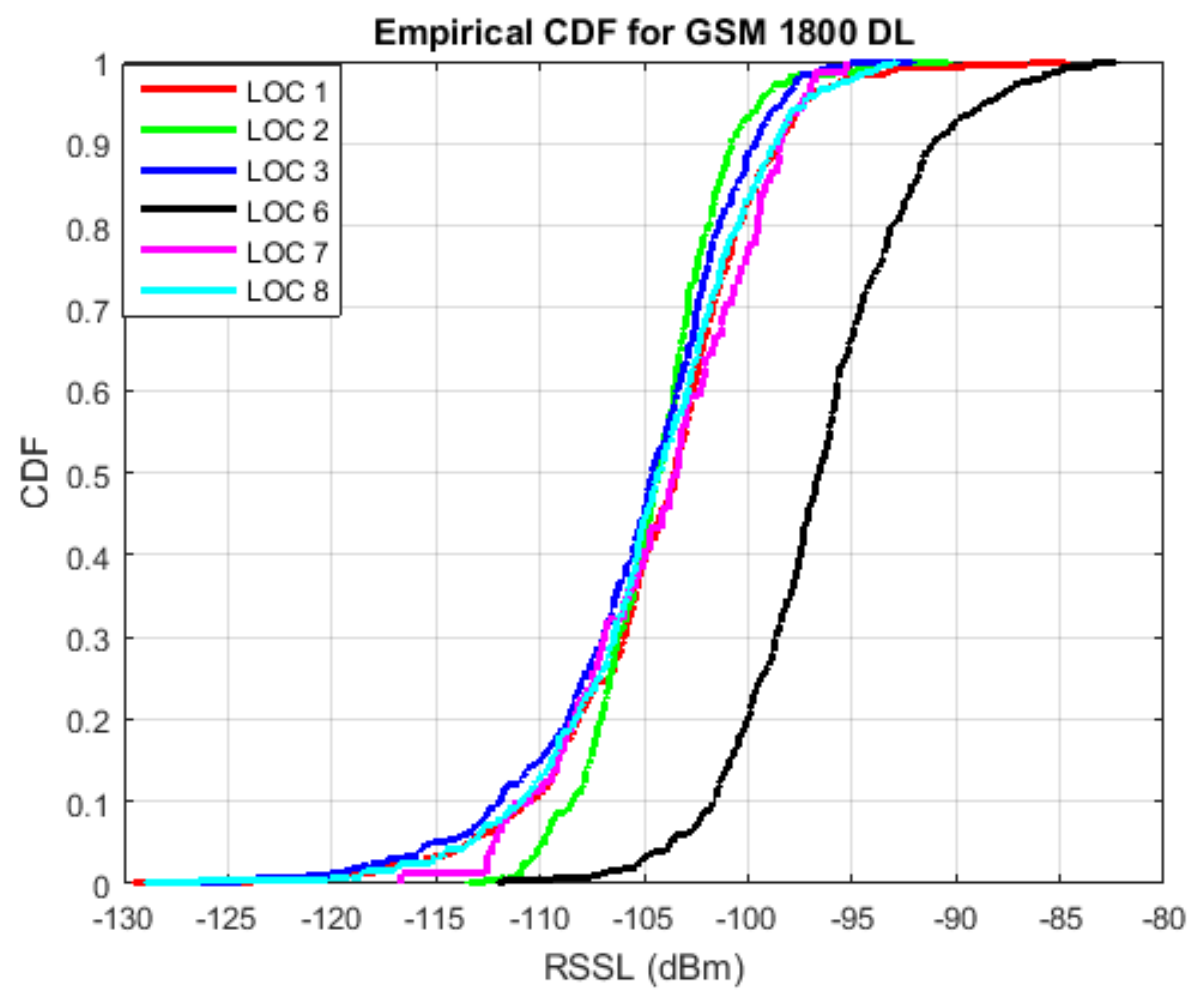

Figure 3. Cumulative Distribution for Received Signal Strength in the GSM $1800 \mathrm{MHz}$ Band for selected Locations.

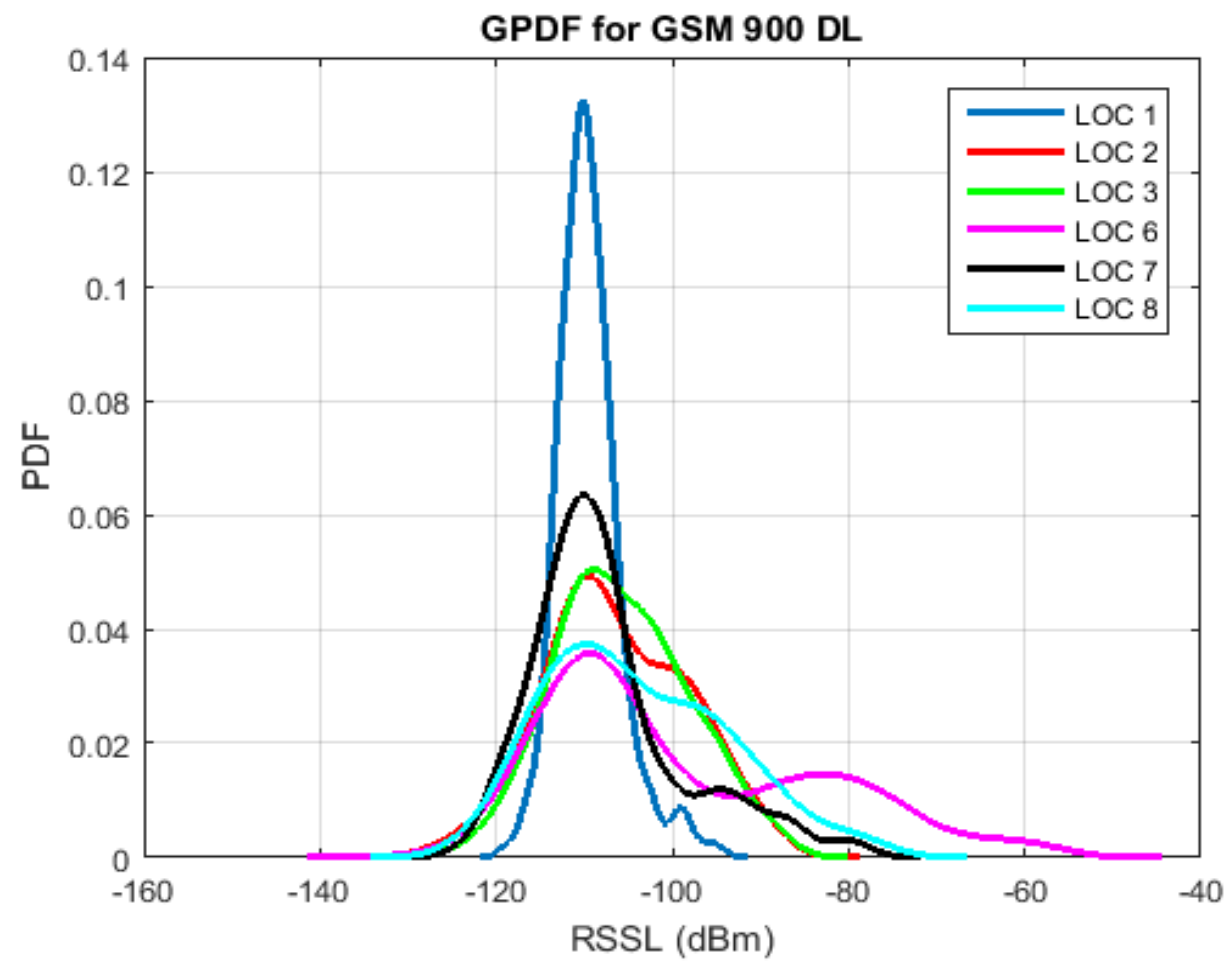

Figure 4. probability Density function for the Received Signal Strength in the GSM $900 \mathrm{MHz}$ Band for selected Locations 


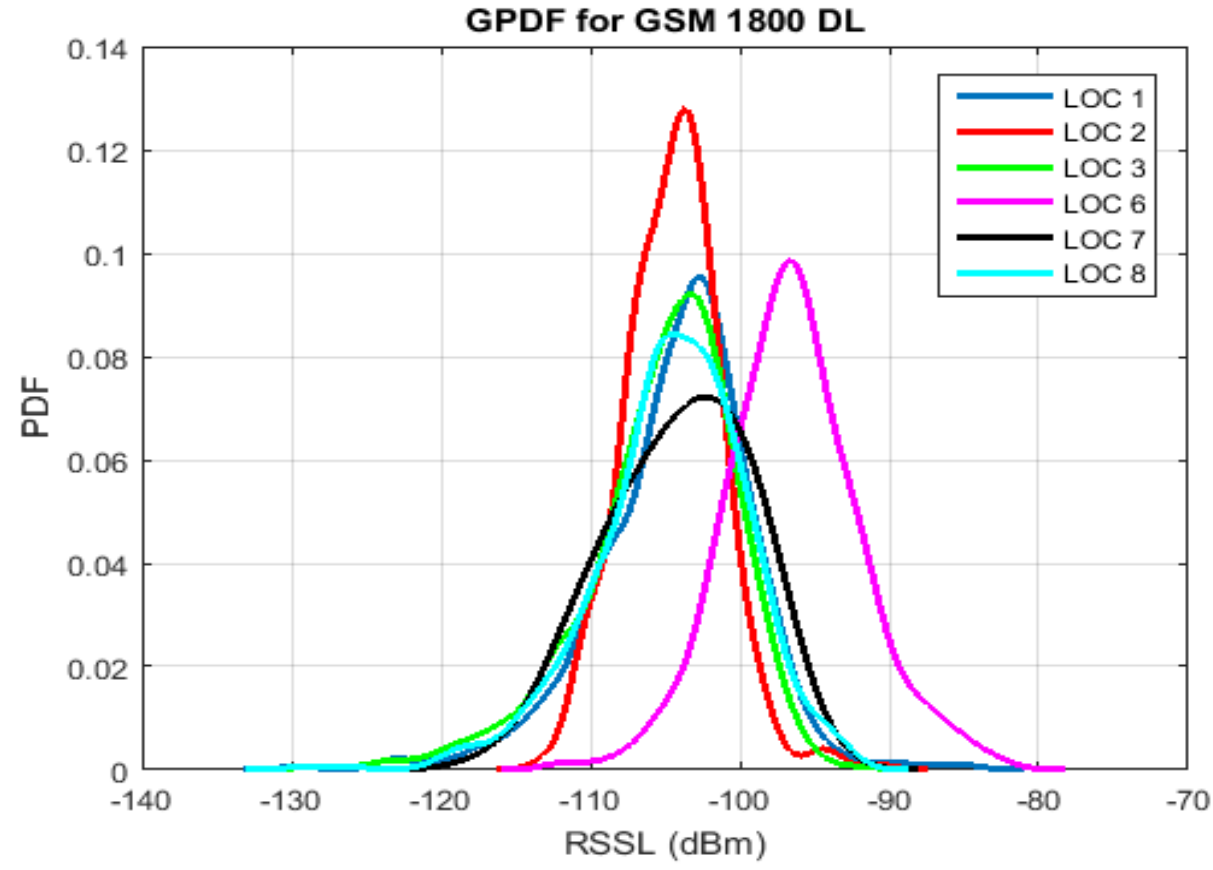

Figure 5. probability Density function for the Received Signal Strength in the GSM $1800 \mathrm{MHz}$ Band for selected Locations

In Figures 4 and 5, we show how the received signal levels are distributed. The results show that Gaussian normal distribution can perfectly be used to represent the distribution of the RSSLs, with locations 1 and 7 showing perfect normal distribution in $900 \mathrm{MHz}$ band, while all the RSSLs for all the locations are normally distributed in the $1800 \mathrm{MHz}$ band. Figs 6 to 11 show the spectrograms of the spectrum occupancy for some selected rural and urban locations. The spectrograms show the location dependent variation of the duty cycle over time.

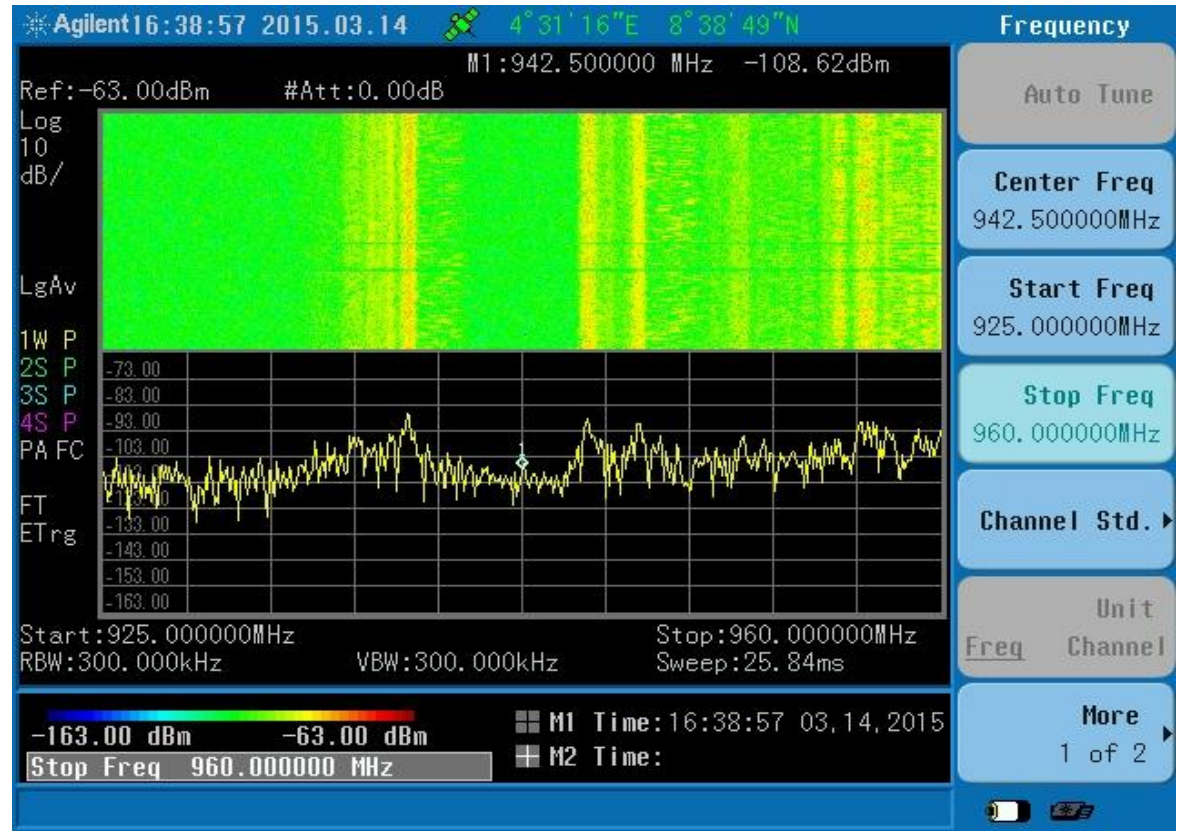

Figure 6. Spectrogram for Location 2 (Malete Village, 4³1'16"E $8^{\circ} 38^{\prime} 49^{\prime \prime} \mathrm{N}$ ) for GSM $900 \mathrm{MHz}$ 


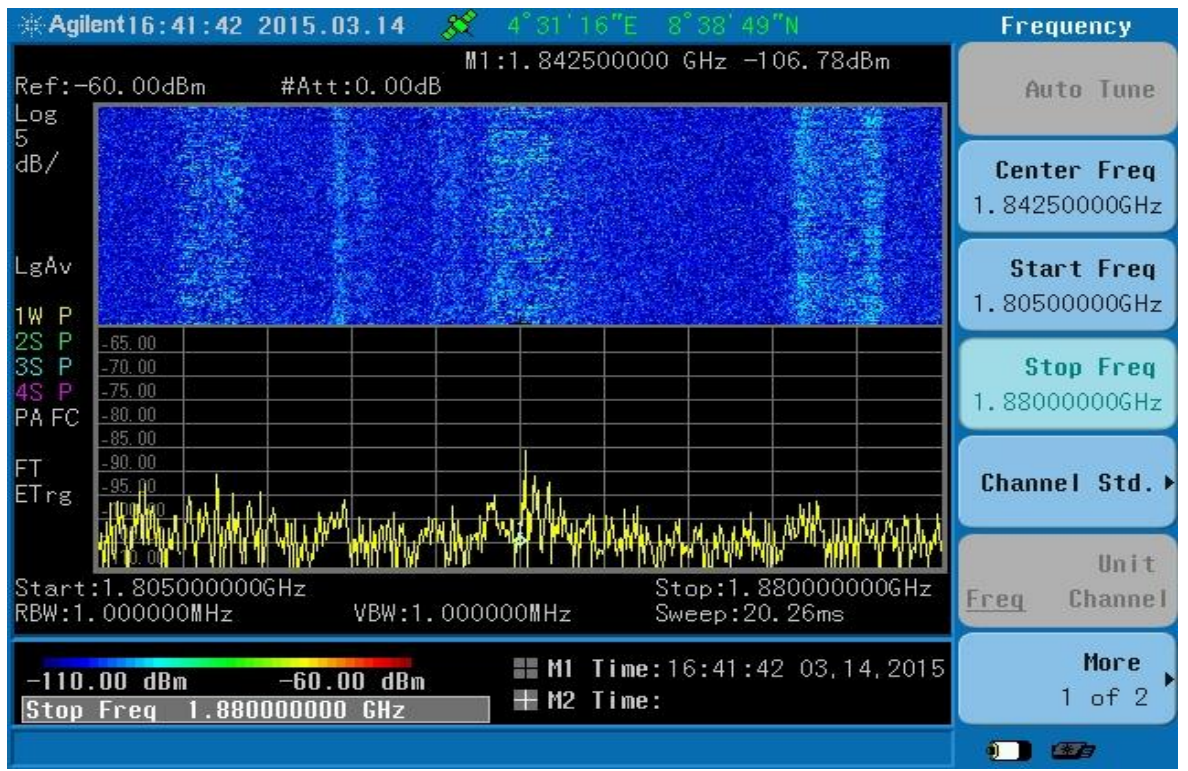

Figure 7. Spectrogram for Location 2 (Malete Village, 431'16"E ; $8^{\circ} 38^{\prime} 49^{\prime \prime N}$ ) for GSM $1800 \mathrm{MHz}$

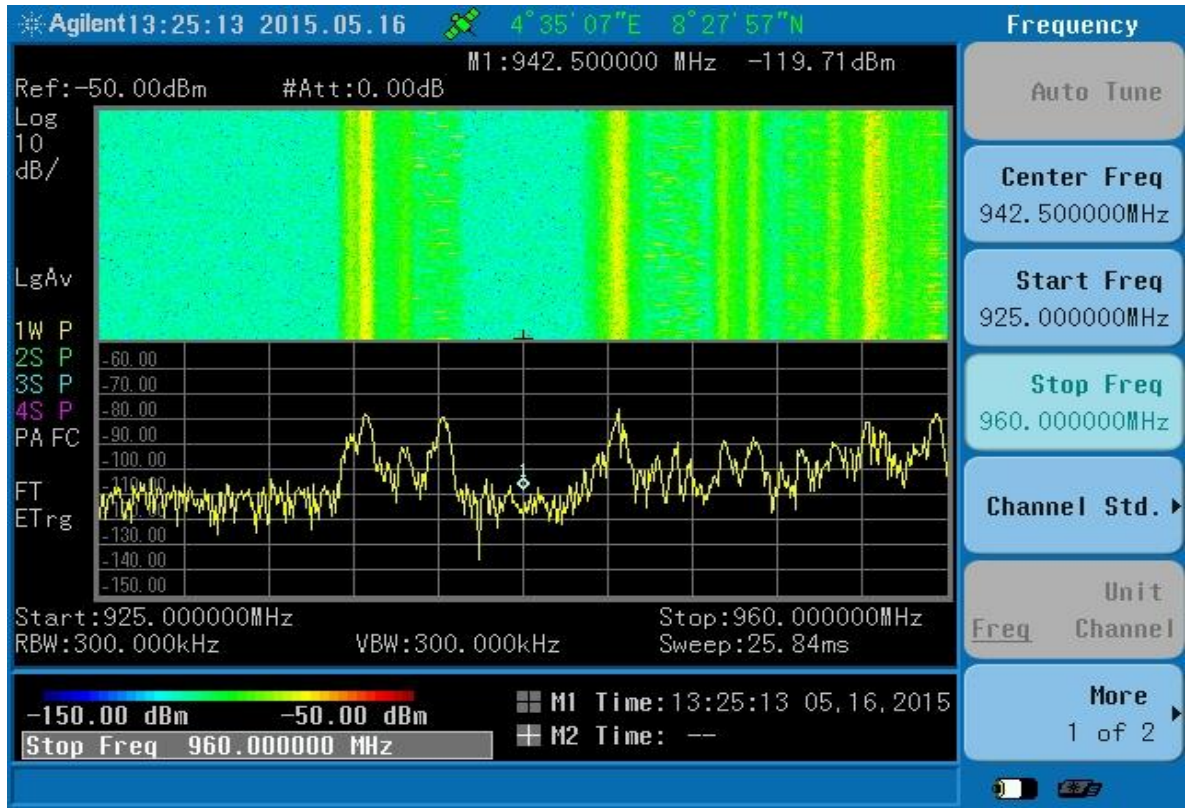

Figure 8. Spectrogram for Location 8 (Pipeline) for GSM $900 \mathrm{MHz}$

In Figures 6 and 7 we provide the spectrograms for the occupancy of LOC 2 (Malete Village, $4^{\circ} 31^{\prime} 16^{\prime \prime E} ; 8^{\circ} 38^{\prime} 49^{\prime \prime} \mathrm{N}$ ) for GSM $900 \mathrm{MHz}$ and $1800 \mathrm{MHz}$ bands. This location is categorised as rural and it could be that no significant activity going on within the bands. However, the spectrum is weakly occupied in the $900 \mathrm{MHz}$ band with occupancy value of $6.9 \%$. Weak signal is spotted on the $1800 \mathrm{MHz}$ as noise, instead of signal, was basically measured. In Figs. 8 to 11 we provide the spectrograms for the occupancy of LOC8 (Pipeline) and LOC 9 (Kwara State Stadium) each for GSM $900 \mathrm{MHz}$ and $1800 \mathrm{MHz}$ bands. All these locations are categorised as urban and significant activities were noticed within the bands. The Pipeline location recorded average spectrum occupancies of $19.28 \%$ and $34.69 \%$ respectively for $900 \mathrm{MHz}$ and 1800 MHz bands. Similarly, the average occupancies of $11.89 \%$ and $31.9 \%$ were measured in Kwara State stadium. These two locations recorded the highest occupancy values. These findings further indicate the spatial variance of the duty cycle across the locations and frequency bands. 


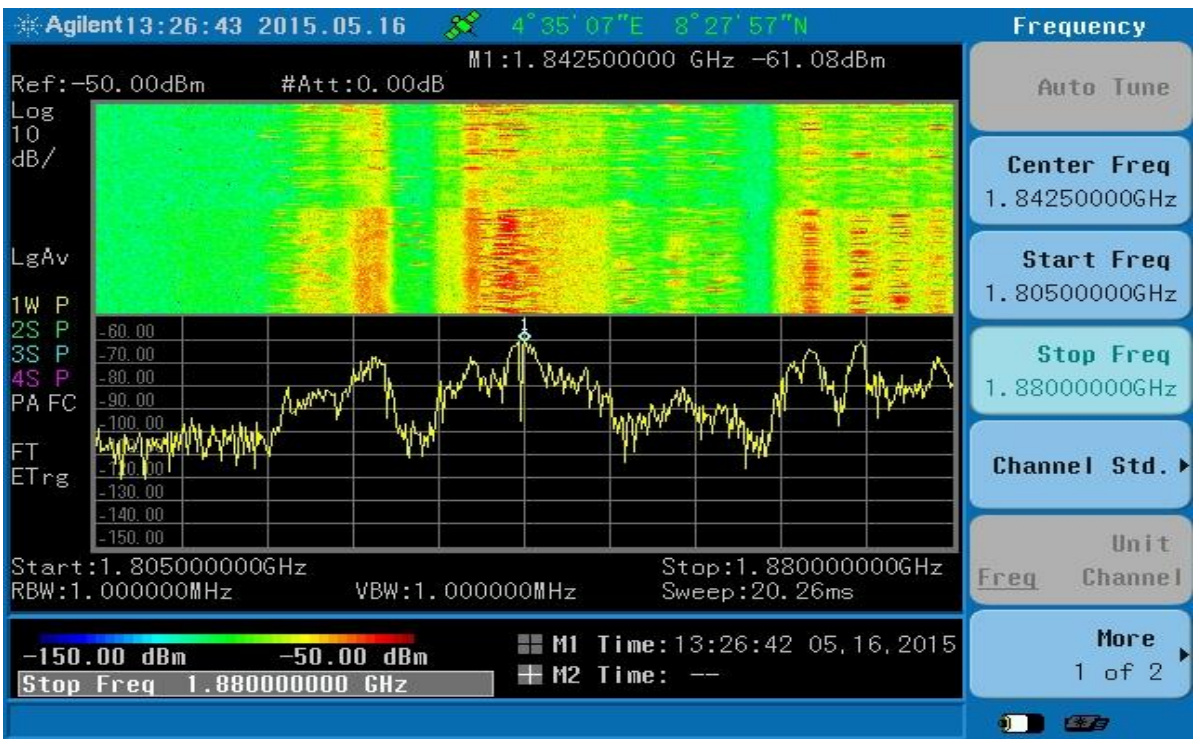

Figure 9. Spectrogram for Location 8 (Pipeline) for GSM $1800 \mathrm{MHz}$

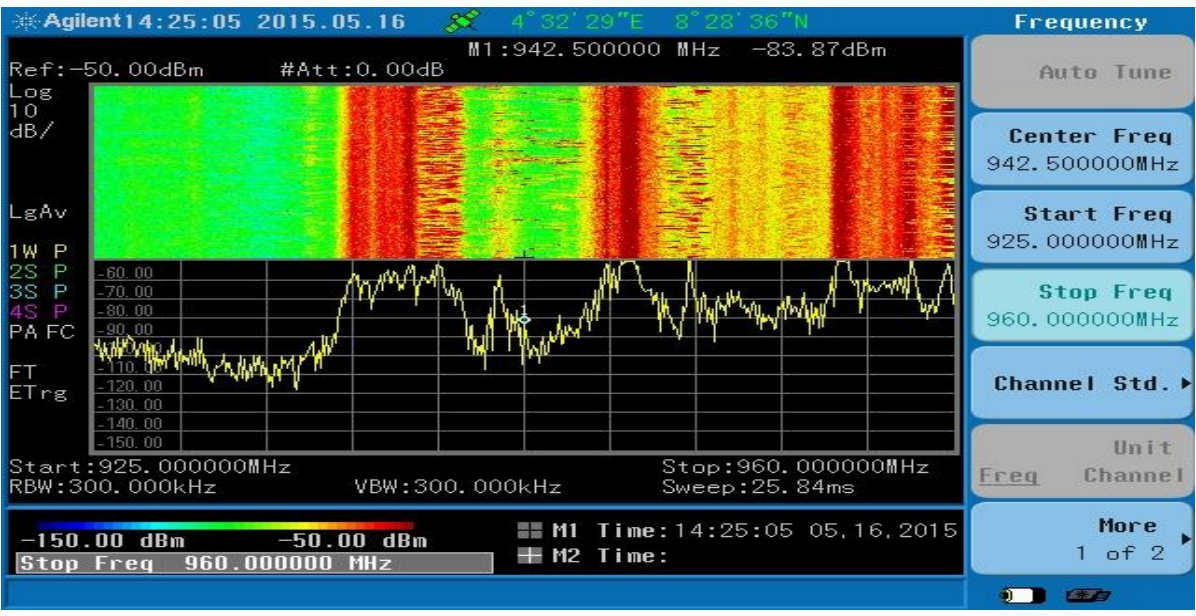

Figure 10. Spectrogram for LOC 9, Kwara Stadium for GSM $900 \mathrm{MHz}$

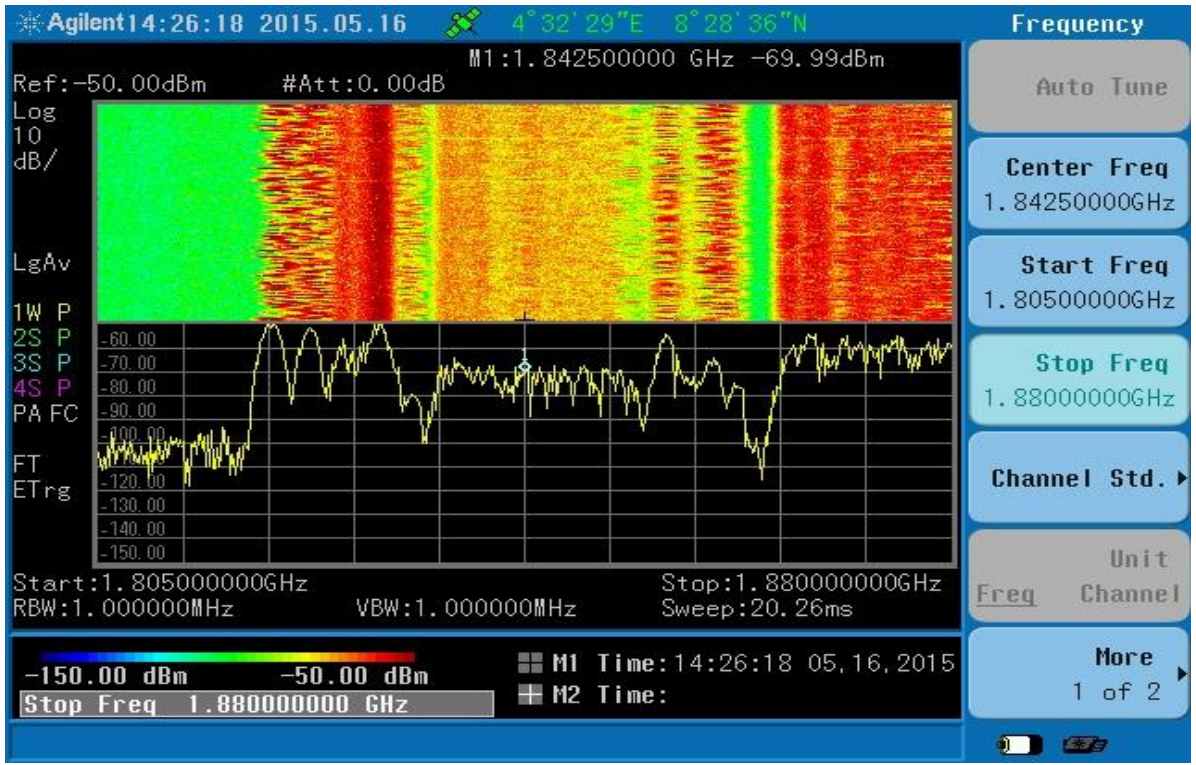

Figure 11. Spectrogram for LOC 9, Kwara Stadiumfor GSM 1800 MHz 
From the findings of this work, the results collaborated with several other measurement campaigns conducted in rural and urban environments. The measurements conducted for ISM bands in [7], 0\% duty cycle were obtained across all the rural areas and average occupancies of $18.56 \%$ and $22.56 \%$ in the urban locations were recorded. It is worth noting that wide disparities were observed between the measured duty cycle in rural and urban locations in [5] [15] [16] and [21]. Even though, these works are not specific to only GSM band, rather, a wide range of frequencies were considered. However, an attempt was made by authors in [9] to study this spatial variance of the duty cycle that exists in the GSM band. The work only addressed the GSM 900 bands. More so, the spatial correlation between the bands and locations are not provided. This work is therefore novel as it addressed the spatial variability of the duty cycle in both GSM 900 and $1800 \mathrm{MHz}$ bands by presenting the results obtained in a spectrum measurement campaign performed over a rich diversity of measurements (i.e. urban and Rural). Furthermore, the work provided the Pearson's correlation coefficient matrix of the duty cycle across the bands and locations. The obtained results indicated that the occupancy level strongly depends on the considered location, with significant variations across the bands.

\section{CONCLUSION}

In this paper, we have examined the spatial variation of duty cycle in the GSM $900 \mathrm{MHz}$ and 1800 $\mathrm{MHz}$ bands for specific rural and urban locations in Ilorin, Kwara State, Nigeria. The results show spatial variance in the duty cycle with average occupancies of $1.67 \%$ and $17.76 \%$ in the rural and urban locations respectively, and an overall of $10.55 \%$ in all locations for GSM $900 \mathrm{MHz}$ band. For the GSM $1800 \mathrm{MHz}$ band, $0.39 \%, 11.00 \%$ and $5.11 \%$ were recorded in the rural, urban and overall locations respectively. Findings also show that there is very high positive correlation between rural $900 \mathrm{MHz}$ and rural $1800 \mathrm{MHz}$ bands, urban 900 $\mathrm{MHz}$ and urban $1800 \mathrm{MHz}$. However, very high but negative correlations were obtained between urban 900 $\mathrm{MHz}$ and rural $1800 \mathrm{MHz}$, and then between urban $1800 \mathrm{MHz}$ and rural $1800 \mathrm{MHz}$. A weak and negative correlation was obtained for rural and urban $900 \mathrm{MHz}$. The correlation for rural-urban $1800 \mathrm{MHz}$ was also negative but higher than $900 \mathrm{MHz}$ band. Furthermore, it was found that Gaussian normal distribution can perfectly be used to represent the distribution of the received signal levels across most of the locations. Findings also indicate that higher duty cycle does not necessarily mean better signal quality and the methodology used in computing the duty cycle metric does not cater for temporal variation of the received signal strength. Therefore, it clearly shows that there is abundance of unutilised spectrum within the GSM band in the rural areas. The telecommunication regulatory commission in Nigeria should adopt useful techniques such as flexible spectrum reuse strategy to relax the regulatory bottlenecks in the regulation of the spectrum in order to maximize the scarce radio resources in the licensed bands, especially for rural network deployments.

\section{REFERENCES}

[1] N. Faruk, et al.,"DTV protection regions for spectrum sharing" The Journal of Enginnering, 5th Sept, 2014, pp 1-3.

[2] N. Faruk, N. T. Surajudeen-Bakinde, Abdulkarim A. Oloyede, Olayiwola O. Bello, Segun I. Popoola, A. Abdulkarim and Lukman A. Olawoyin, "On Green Virtual Clinics: A Framework for Extending Health Care Services to Rural Communities in Sub-Saharan Africa," IEEE International Rural and Elderly Health Informatics Conference (IREHI) Lome, Togo, 14 -17 December 2017

[3] Takashi Kosugi, Takeo Fujii, "Efficient spectrum sharing with avoiding spatial fragmentation of white space," ICT Express 1 (2015) 55-58.

[4] S. Haykin, "Cognitive radio: Brain-empowered wireless communications," IEEE J. Sel. Areas Commun. 23 (2) (2005) 201-220.

[5] M. López-Benítez and F. Casadevall "Spectrum Occupancy in Realistic Scenarios and Duty Cycle Model for Cognitive Radio" Advances in electronics and telecommunications, vol. 1, no. 1, April 2010

[6] B. Gafai, N.F. Wenjiang, C. Kadri "An Insight into Spectrum Occupancy in Nigeria" IJCSI International Journal of Computer Science Issues, Vol. 10, Issue 1, No 1, 2013, pp 394-399.

[7] A.A. Ayeni et al.," Spectrum Occupancy Measurements and Analysis in the 2.4-2.7 GHz Band in Urban and Rural Environments", International Journal of Future Computer and Communication, Vol 5, no 3, 2016.

[8] A. A. Ayeni et al. "Spatial Spectrum Utilization Efficiency Metric for Spectrum Sharing System," Intr J of Digital Information and Wireless Communication, IJDIWC, vol 5, No 1. pp 44-51, 2015.

[9] N. Faruk., Yusuf Imam-Fulani, Ismaeel A. Sikiru, Segun I. Popoola, A.A. Oloyede, Lukman A Olawoyin, N. T. Surajudeen-Bakinde and A.O. Sowande, "Spatial Variability Analysis of Duty Cycle in GSM Band", in proc. IEEE NIGERCON, Imo State, Nigeria, 7th-11th November, 2017. pp 163-166.

[10] Y. Wei, Seung-Hoon Hwang, "Investigation of spectrum values in rural environments", ICT Express 4 (2018) 234238.

[11] L. Yin, K. Wu, S. Yin, S. Li, and L. M. Ni, "Reuse of GSM White SpaceSpectrum for Cognitive Femtocell Access," In Parallel and Distributed Systems (ICPADS), 2012 IEEE 18th International Conference on, pages 1-7.IEEE, 2012.

[12] S.Hasan, K. Heimer, K. Harrison, K. Ali, S. Roberts, A. Sahai and E. Brewer "GSM whitespaces: An opportunity for rural cellular service," 2014 IEEE International Symposium on Dynamic Spectrum Access Networks (DYSPAN), McLean, VA, 2014, pp. 271-282.doi: 10.1109/DySPAN.2014.6817804 
[13] M. B. H. Weiss, "Spatio-temporal spectrum holes and the secondary user," 2011 IEEE International Symposium on Dynamic Spectrum Access Networks (DySPAN), Aachen, 2011, pp. 216-222.

[14] O.D. Babalola et al.," Short-Term Variation of Duty Cycle in the VHF and UHF Bands", in proc. IEEE International Conference on Cyberspace, Abuja, 4-7 Nov. 2015, pp 197-201.

[15] O.D. Babalola et al.," Spectrum Occupancy Measurements in the TV and CDMA Bands", in proc. IEEE International Conference on Cyberspace, Abuja, 4-7 Nov. 2015, pp 192 - 196.

[16] N. Faruk et al. ," Large Scale Spectrum Survey in Rural and Urban Environments within the $50 \mathrm{MHz}-6 \mathrm{GHz}$ Bands", Measurement, Elsevier, Vol. 91, September 2016, Pages 228-238.

[17] I. Şeflek, and E. Yaldız, "Spectrum occupancy measurements at university campus in Turkey," International Journal of Electronics and Electrical Engineering, 2017, 5(1), pp.1-6.

[18] M. L. Attiah, A. A. Md Isa, Zahriladha Zakaria, M. K. Abdulhameed, Mowafak K. Mohsen, Ahmed M. Dinar, "Hybrid multi-independent mmWave MNOs assessment utilising spectrum sharing paradigm for 5G networks," TELKOMNIKA, Vol.17, No.3, June 2019, pp.1101 1109. DOI: 10.12928/TELKOMNIKA.v17i3.11131.

[19] A. Al-Hourani, V. Trajković, S. Chandrasekharan, and S. Kandeepan, "Spectrum occupancy measurements for different urban environments," In European Conference on Networks and Communications (EuCNC), 2015, (pp. 97 102).

[20] I. A. Sikiru, Faruk. N, Yusuf Imam-Fulani, Segun I. Popoola, A.A. Oloyede, Lukman A Olawoyin, "The Effects of Detection Threshold and Frame Size on Duty Cycle in GSM Bands", in proc. IEEE NIGERCON, Imo State, Nigeria, 7th-11th November, 2017. pp 343-346.

[21] Marţian, A. L. E. X. A. N. D. R. U., "Evaluation of spectrum occupancy in urban and rural environments of Romania”, Revue Roumaine des Sciences Techniques-Electrotechn. et Energ 2014, pp 87-96. 